\title{
Biyoloji Dersinde Bazı Makroskobik Kavramlara İlişkin Ders Materyalinin Geliştirilmesi*
}

\section{Nasip DEMIRKUŞ**, Nimet BATIHAN GÜZEL***}

Öz: Kavramlar, bilimin yapı taşları gibidir. Canlılar için hücre ne kadar önemliyse; kavramlar da bilim için o kadar önemlidir. Kavramların eksik veya yanlış öğrenilmesi, düşünce ve eylem yanılgısına neden olur. Örneğin: kemik dokuda; boyuna uzanan sinir ve kan damarlarının geçtiği kanala Havers kanalı denir. Buna Havers kanalı yerine, uzun kemik kanalı demek bize daha kolay çağrışım yapar.

$\mathrm{Bu}$ mantıktan hareketle, çalışmada, biyolojideki önemli makroskobik kavramların tanımlarını ve görsellerini; basılı yayınlardan, internet ve diğer medya ortamından toplamıştır. Bu çalışma da 800 kavrama ait 5000 görüntü ve tanımları internet destekli olarak hizmete sunulmuştur.

Biyolojik kavramlar, Adobe Dreaweaver web editöründe düzenlenerek, harf sırasına göre dizilerek: http://www.biyolojiegitim.yyu.edu.tr/kav/indexa.htmweb adresin de internette açık hale getirilmiştir. Ayrıca FlipAlbum 6.0 Suite kullanılarak internet ve internal linkli kavram sanal kitabı hazırlanmıştır.Yabancı bazı kavramlara karşılık gelen Türkçe yeni kavramlar önerilmiştir.

Anahtar kelimeler: Biyoloji Öğretimi, MakroskobikBiyoloji Kavramları, Ders Materyali

\footnotetext{
* Bu çalışma, 23-25 Mart 2018 tarihlerinde yapılmış olan Uluslararası Bilim ve Eğitim kongresinde (UBEKICSE) bildiri olarak sunulmuştur ve Nimet BATIHAN'IN " Biyoloji İle İlgili, Önemli Makroskobik Kavramlara İlişskin Ders Materyali Geliştirmek " adlı yüksek lisans tezinden hazırlanmıştır.

** Prof. Dr. Yüzüncü Yıl Üniversitesi, Eğitim Fakültesi, Matematik ve Fen Bilgisi Eğitimi Bölümü Biyoloji Eğitim ABD. nasip@hotmail.com , Orcid ID 0000-0003-4195-070X

**MEB de Öğretmen, İstanbul, Türkiye
}

Gönderim:05.08.2019 Kabul:19.09.2019

Yayın: 20.10.2019 


\section{Developing Course Material on Important Macroscopic Concepts Related to Biology}

Abstract:The concepts are like building blocks of science. How important the cell is for living things; concepts are so important for science. Learning the concepts incompletely or incorrectly causes misconception and action. For example: in bone tissue; the nerves extending in the longitudinal direction and the blood vessels pass through are called the Havers channel. It makes it easier for us to associate Havers with channels instead of channels with long bone channels.

With this logic, our work also includes definitions and visuals of important macroscopic concepts in biology; we have gathered from print publications, internet and other media environment. In this study, descriptions of 800 concepts and 5000 images were presented to the internet.

Biological concepts are arranged in the Adobe Dreaweaver web editor, sorted by letter order:

http://www.biyolojiegitim.yyu.edu.tr/kav/indexa.htmweb address has been made open to the internet. In addition, using FlipAlbum 6.0 Suite, internet and internal link concept virtual book is prepared.

New concepts in Turkish corresponding to some foreign concepts have been proposed.

Keywords:Teaching Biology,Macroscopic Concepts of Biology,Course Material

\section{Giriş}

Teknolojideki gelişmelerle birlikte kavram öğretiminde de yeni yaklaşımlara gereksinim duyulmaktadır. Kavramları anlatırken olabildiğince farklı görsel ve işitsel kaynaklardan yararlanmak anlatımı kolaylaştıracağı gibi; dersleri de daha zevkli hale getirecektir. Bunun için de kavramların farklı kaynaklardan yararlanılarak doğru öğretilmesi büyük önem taşır(Demirkuş \& İlçin, 2016; Wald, 1992).

Özellikle biyoloji bölümünden mezun öğretmenlere, ortaöğretim öğrencilerine ve biyoloji bölümlerindeki öğrencilere hizmet vermek amacıyla internet üzerinden kavramların tanımları daha doğru, net ve zihinsel yönden doyurucu örneklerle verilmeye çalışılmalıdır. Ülkemizde ilk, orta ve yükseköğretimde verilen biyoloji derslerine ait temel biyolojik kavramların daha mükemmel öğretilmesi, eksik veya yanlış öğretilmesinin telâfi edilmesi için 
internet ve medya araçları kullanılmaya çalışılmıştır. Biyoloji ile ilgili öğrenci ve öğretmen kitlesine, internet üzerinden ulaşılarak, kavram yanılgısının ve yanlış öğretiminin telâfi edilmesi çok büyük önem taşımaktadır. Ayrıca kavramların mantıklı ve zihnimize yatkın, çağrışımı kolay, Türkçe karşılıklarıyla ortaya konması da bir o kadar önem taşımaktadır(Demirkuş ve Gülen, 2017; Gülen,2015;2016a;2016b;2018).

Eğer kavramlar doğru ve kolay çağrışılabilir bir mantıkla üretilmezse ve öğretilmezse bunun dezavantajı etkin bir şekilde hayatın her aşamasında kendini hissettirir. Hücreler beden için, ne anlam ifade ediyorsa; kavramlar da bilimler için aynı anlamı ifade eder gibidir. Bir dilde kavramlar ve kavramlar arası ilişkiler ne kadar doğru, sade ve mantıklı alt ünitelerden ve dinamik ilişkilerden oluşursa o kadar sağlıklı olur.

Kavramların kolay anlaşılabilmesi için; sunumda görsel-işitsel araçların ve materyallerin kullanımı gerekmektedir. Kullanılan bu araçlar ile öğretmen ve öğrencilerin biyolojideki, doğa bilimlerindeki bilgi eksikleri giderilecek, doğruyu öğrenme arzusu oluşturulabilecek ve hatta bu alanlardaki başarılarını arttıracaktır. Kavramlar biyoloji biliminin temelidir. Kavramlar kolay anlaşılır, açık bir dille tanımlanarak ve onu en güzel izah edecek görsel, işitsel sanal ortamda hazırlanan materyallerle desteklenirse sağlam temeller oluşturulur.

Son yıllarda, grafik editörü, video editörü, kavram editörü, sanal kitap editörü vb. sanal araçlar konusunda değişik gelişmeler olmaktadır. Örneğin birçok okulda evimizde ve çalışma ortamımızda, bilgisayar bulunmaktadır. Öğrenciler, öğretmenler bu çalışma ile bilgisayardan konuyla ilgili hazırlanan CD veya internet sitelerinden biyoloji kavramlarıla ilgili eksiklerini giderebilecek ve yanlışlarını telâfi edebileceklerdir.

Biyoloji tüm pozitif bilimlere ait her türlü envanterin hayata doğru uygulandığı ve hayat bulduğu bir bilim dalıdır. 21. yüzyılın gözde bilimi biyoloji merkezli fen bilimidir. Biyoloji, özellikle doğa döngüsü dikkate alınarak hayatın uzaya taşınması, uzayda yeni gezegenlere canlıların mayalanması konularında Uzay Biyolojisi başlığı altında insanlığa hizmet verebilecek alternatif bir bilim dalıdır (Demirkuş, 2009;2009a, 2009b; 2009c; 2009d).

Biyolojinin fen bilimleri içinde en fazla gelişme ve ilerleme kaydettiği belirtilmekte ve bu gelişmenin daha da artan bir şekilde devam edeceği vurgulanmaktadır. Bu nedenle eğer bilimsel bir ders plânlanmasından söz edilecekse biyolojiye en fazla yerin verilmesi gerekmektedir. Çünkü biyolojik tekniğin ulaştığı bugünkü basamak, gerek gen teknolojisi ve gerekse ekolojideki konular insanlığı içinde bulunduğu durumdan kurtaracak boyutlardadır. $\mathrm{Bu}$ bir başlangıçtır. Biyoloji dersinde, canlının önemli bir konumda olduğu, yaşama alanında öğrencinin nasıl davranması gerektiği verilmeli, onun çevreyi desteklemesi gerektiğini 
vurgulamalı; çevrede rastlanan canlıları, objeleri doğru algılamasını, düzenlemesini ve adlandırmasını öğretmelidir (Kiziroğlu, 1988).

Biyoloji derslerinde doğada var olan biyolojik mantık sistemlerini kavramak, bunları anlaşılabilir bir dille öğrencilere aktarmak ve hayata doğru uygulamak genel amaç olmalıdır. Öğrencilerin edindikleri bilgileri, doğal döngüye zarar vermeden insanlık menfaatleri için hayata uygulamaları istenmektedir (Demirkuş, 1999; Demirkuş, Acar,ve Gülen, 2018).

Biyoloji kavramları ile ilgili temel bilgi ve görüşler verilirken bu arada karşımızdakinin algılama, düşünme kabiliyetini geliştirmelidir. Açık seçik bir kavram oluşturmak için gereken temel bilgi ve olanaklar anlaşılır bir şekle sokulmalıdır. Özellikle kavramlar ve isimler seçilirken ya da tanımları yapılırken, öğrencilerin kelime ve bilgi dağarcığı, yaşadığı çevre dikkate alınarak öğretilmelidir (Bozcuk, 1995).

Özellikle Doğu ve Güneydoğu bölgelerinin bazı yörelerinde evde ve yakın çevrelerinde Türkçe konuşulmaması ya da az konuşulması çocukların eğitimlerinin niteliğini etkilemektedir. Bu nedenle öğrenciler okulda dersleri takip edebilme yönünden güçlüklerle karşılaşmaktadırlar. $\mathrm{Bu}$ açıdan öğrencilere biyoloji ilgili kavramları anlatırken görsel-işitsel araçlar kullanılmalıdır (Gürlek, 2019).

Teknolojideki gelişmelerle birlikte kavram öğretiminde de yeni yaklaşımlara gereksinim duyulmaktadır. Kavramları anlatırken olabildiğince farklı görsel ve işitsel kaynaklardan yararlanmak anlatımı kolaylaştıracağı gibi; dersleri de daha zevkli hale getirecektir. Bunun için de kavramların farklı kaynaklardan yararlanılarak doğru öğretilmesi büyük önem taşır.

$\mathrm{Bu}$ bilgilerin ışığında çalışmanın amacı, biyoloji bölümünden mezun öğretmenlere, ortaöğretim öğrencilerine ve biyoloji bölümlerindeki öğrencilere hizmet vermek amaciyla internet üzerinden kavramların tanımları daha doğru, net ve zihinsel yönden doyurucu örneklerle verilmeye çalışılmıştır

\section{Materyal ve Yöntem}

Van Yüzüncü Yıl Üniversitesi Eğitim Fakültesi Biyoloji Eğitimi Anabilim Dalı, Materyal Geliştirme ve Hazırlama Odasında bulunan 120 campreparata ait,1340 tane görüntü mikroskop ve CCD Colour Video Camera VC 3031 cihazı kullanılarak yararlanılmıştır. Medya ortamında ki çeşitli basılı kaynaklardan yararlanılmıştır (Atlas, 1994; Ayaz ve Demirkuş, 2017; Bakırcı, 2010; Bozcuk, 1995; Börü,Öztürk veCavak, 2002; Campbell, 1999; Cihangir, 2009; Claude, 1979; Güner veAysel, 1992;Korkmaz, Bulut, Sağdıç,, 1998; Kiziroğlu, 1988; Seçmen, 
1995; Sucu,Bayar ve Küpeli, 2001; Tootlille, 1983).Google arama motorun da; "biological concepts", "misconception", "biology concepts" tanımları ile ilgili olarak tarama kurallarına uygun arama yapılmıştır (Arizona Üniversitesi, 2001; Mission, 2011).

İnternet ortamındaki TUBİTAK Bilim Teknik Dergisine ait geçmişteki sayılarından biyolojiyle ilgi kavramları içeren makalelerden yararlanılmıştır (Van Yüzüncü Yı1 Üniversitesi, 2019). Bu makalelerden çeşitli biyoloji sözlüklerin tanımlarından yararlanılmıştır. Ayrıca tez danışmanı tarafından biyolojiyle ilgili çekilmiş fotoğraflar ve ders notlarındaki bilgiler kullanılmıştır.

Özellikle kavramların doğru, mantıklı, kolay çağrışım yapan Türkçe karşılığını bulmak için, Türk Dil Kurumu Sözlüğü, Redhouse Sözlüğü ve Babylon sözlükleri kullanılmıştır. Biyoloji Anabilim Dalı Materyal Geliştirme ve Hazırlama Odası'ndaki 15000’e yakın görüntü ve sanal öğrenci ödevi koleksiyonundan yararlanılmıştır. Toplamda çalışmada 800 kavrama ait 5000 tane görüntü seçilmiştir. Bu görüntülerin bir kısmı tarafımızdan taranan dergilerden alınmıştır. Bir kısmı da mikroskop ve fotoğraf makinesiyle çekilip dijital ortama aktarılan görüntülerdir.

Bütün resimler Adobe Photoshop CS sanal grafik aracı ile rötuşlanmıştır. Bazıları yeniden boyutlandırılmış ve orijinal olanların üzerine isim yazılmıştır.

-Gif formatındaki resimlerin tamamı jpeg formatına çevrilerek web'e hazır hale getirilmiştir.

-Adobe Dreamweaver web editörü ve Adobe Fireworks programları kullanılarak kavram tanımları ile resimler eşleştirilip, internete hazırlanmıştır.Bu aşamada yaklaşık 40 tane sanal sözlükten faydalanılmıştır.

İnternete hazır hale getirilen kavramlar ve içerdikleri internet linkleri, intranet linkleri olduğu gibi FlipAlbum 6.0 Suite sanal kitabına yapıştırılarak CD'si hazırlanmıştır. Sanal kitap CD'si ile internete bağlı olan bir bilgisayarda dinamik olarak hem internetteki linklere hem de sanal kitap içindeki linklere ulaşmak mümkündür.

\section{Bulgular}

Araştırmada, Biyoloji ile ilgili kavramların doğru algılanması ve öğrenilmesi için; seçilen materyalin özelliklerinin yanı sıra, aynı materyalin üzerinde gösterilebilecek veya tanımlanabilecek farklı kavramlar, aynı kavramı izah etmeye yönelik birden fazla materyale gereksinim duyulabilmektir.

Bu çalışmalar sırasında, basılı medya araçları ve internet üzerinde biyolojik kavramlarla ilgili yanlış ve eksik kavram öğrenmenin (kavram yanılgısı) veya öğretimin sebep olduğu 
olumsuz durumları ortadan kaldırmaya ya da çözümüne yönelik kapsamlı net öneri ve çalışmalara rastlanmamıştır. Mevcut olanlar da çok yetersizdir.

Bu modelin daha da ileri gidilerek Van Yüzüncü Yıl Üniversitesi Eğitim Fakültesi Biyoloji Eğitimi Anabilim Dalı'nda intranet, internet ortamındaki kısa metrajlı filmler, animasyonlar ve PowerPoint sunularından kavramlar arasına link atılması ile kavram öğretiminin zenginleştirilebileceği ortaya çıkarılmıştır.

Bu çalışmanın diğer disiplinlerdeki benzer çalışmalara örnek olması önemlidir. Zihinsel olarak daha tatmin edici, tartışmaya açık, görsel, sesli, tanımlanmış (kısa film); kavram-tanım ilişkisi modeli daha sonra aynı yazarlar tarafından sunulmuştur (Demirkuş ve Gülen, 2017).

Ayrıca bazı kavramların birden çok tanımları veya çok yönlü anlamları olabileceği belirlenmiştir. Örneğin: Bazı kavramların biyolojideki, kimyadaki hatta biyolojinin alt dallarındaki tanımları farklı olabilir. Aynı kavramın farklı anlamlar taşıyabileceği de belirlenmiştir. Bunun tam tersinin de mümkün olduğu tespit edilmiştir. Farklı kavramların tanımları örtüşebilir. Bu amaçla biyoloji ders kitapları yazılırken, içerdikleri kavramlar açısından özel bir model ve yöntemle yazılmasının gereği ortaya çıkarılmıştır.

\section{Sonuç ve Öneriler}

$\mathrm{Bu}$ çalışması ile ilk, orta ve yükseköğretimdeki biyoloji dersleri ile ilgili temel makroskobik kavramların daha doğru öğrenmeye ve eksikleri tamamlamaya, yönelik internet web sayfası ve sanal kitap CD’si hazırlanmıştır.

Literatürdeki bilgiler bu açıdan, yetersiz ve dağınıktır. Bu çalışma ile bu bilgileri daha anlaşılır bir hâle getirilmiştir. Uluslararası seviyede ki görüntü linkleri ve kavramların birbirleriyle olan ilişkisine dayalı bir ön çalışmadır. Asıl amaç bundan sonra diğer sahalarda da benzer çalışmalar yapılması için örnek teşkil etmektedir (Ayaz ve Demirkuş, 2017).

Bu yüksek lisans tez çalışması ile öğrencisi bazı grafik programlarını, web editör programlarını, dijital ortama materyal hazırlamaya yönelik, gerçek ve sanal araçları etkili bir biçimde kullanmayı öğrenmiş ve becerilerini geliştirmiştir.

Öğrenci ödevleri, uygulamalar ve laboratuvar çalışmalarından elde edilen verilerden hareketle öğretimde kavramların doğru anlaşılması, öğrenilmesi, uygulanması ve kullanılması için, sanal veri toplama, değerlendirme ve işlemesine yönelik "Sanal Veri İşleme Yöntemi" geliştirilmiştir. 
Toplanan veriler daha ekonomik olan sanal ortamda kullanabilir hale getirilmiştir. Gelecekte yapılabilecek benzeri eğitim öğretim çalışmaları için veri kaynağı oluşturulmuş ve bu tip çalışma yapacaklara yönlendirici bir kaynak oluşturulmuştur (Aras, 2011).

Biyoloji ve Fen Bilgisi Laboratuvarındaki etkinlik, uygulama sonucu toplanan ve hazırlanan materyaller sanal ortama aktarılmıştır. Kaliteli ve düşük maliyetli sanal ders materyali hazırlanmıştır. Bu amaçla; biyoloji ile ilgili ve önemli (öğretimde en çok kullanılan) yaklaşık 800 kavramın tanımına ait, 5000 görüntünün bir görsel havuzu oluşturulmuştur. http://biyolojiegitim.yyu.edu.tr/kav/indexa.htm, http://nadidem.net/kav/indexa.htm http://biyolojiegitim.yyu.edu.tr/la/index.htm, http://nadidem.net/la/index.htm http://biyolojiegitim.yyu.edu.tr/fbl/index.htm , http://nadidem.net/fbl/index.htm http://biyolojiegitim.yyu.edu.tr/lab/index.htm , http://nadidem.net/lab/index.htm Kavramların öğretimin de, aşağıda belirtilen hususlara dikkat edilmesi önerilmektedir.

-Ders kitapları hazırlanırken mutlaka içerdikleri tüm kavramlar görüntülü, internet ve iç linkli sanal kitapları ile desteklenmelidir.

-Kavramlar mümkünse görüntülü, kısa filmli, animasyonlu CD’lerle öğretilmelidir.

-Kavramlar tartışma, soru-cevap, uygulama ve benzeri yöntemlerle kavratılmalıdır.

-Öğretimin uygun kademelerine kavram dersleri konulmalıdır.

-Kavramların dilde ki en anlaşılır, kolay çağrışımlı ve mantıklı karşılıkları verilmelidir.

-Yeni (yabancı) kavramlara ait yıllık raporları hazırlanmalıdır. Bu rapor ve öneriler internette tartışmaya açılmalıdır.

-Kavram öğretiminde; kavramların zihinde güncellenmesi ve yerleştirilmesi konusundaki çalışmalara yoğunluk kazandırılmalıdır.

-Kavramlar öğretimde ki önem dereceleri önceliklerine göre (1. 2. ve 3. derecedeki kavramlar olarak) derecelendirilmeli öğretilip, güncellenmelidir.

\section{Makalenin Bilimdeki Konumu}

Matematik ve Fen Bilimleri Eğitimi Anabilim Dalı/Biyoloji Eğitimi

\section{Makalenin Bilimdeki Özgünlüğü}

Biyolojiyle ilgili kavramların, Türkçeleştirilmesi, varsa farklı tanımlarının verilmesi ve tanımları en doğru şekilde ifade eden görsellerle internet ortamında sunulması önemlidir. Yürüklükteki eğitim sistemine ait ders kitaplarında ve sanal ortamda kavramlara yeterince liyakatli önem ve ayrıcalık verilmediği görülmektedir(Akkaya,Albayrak, Öztürk ve Cavak, 2011; Akkaya,Albayrak, Öztürk, Cavak, Sağdıç, Öztürk ve İlhan, 2011a; Akkaya, Albayrak, 
Öztürk, Cavak, Sağdıç ve Öztürk, 2011b;MEB Komisyonu 2011). Bu çalışma, diğer alanlarda da yapılması açısından örnek oluşturacak özgünlüktedir. Ancak bu çeşit çalışmalarla kavram yanılgısının azaltılacağı kanaatindeyiz

\section{Kaynaklar}

Akkaya, S., Albayrak, O., Öztürk ve E. Cavak, Ş. (2011). 9. Sinıf Biyoloji Ders Kitabı MEB. Devlet Kitapları, Milli Eğitim Basımevi, 275, İstanbul.

Akkaya, S., Albayrak, O., Öztürk, E.,Cavak, Ş., Sağdıç, D., Öztürk, E. ve İlhan, F.(2011a). 10. Sınıf Biyoloji Ders Kitabı MEB. Devlet Kitapları, Milli Eğitim Basımevi, 264, İstanbul.

Akkaya, S., Albayrak, O., Öztürk, E.,Cavak, Ş., Sağdıç, D. ve Öztürk, E., (2011b).11. Sinıf Biyoloji Ders Kitabı MEB. Devlet Kitapları, Milli Eğitim Basımevi, 274, İstanbul.

Aras, S.( 2011). Biyoloji Bilimi Kavramları,02 Mayıs 2019 tarihindehttps://biolojialemi.tr.gg adresinden alınmıştır.

Arizona Üniversitesi, (2001). The Biology Project, 2 Mart 2019 tarihinde http://www.biology.arizona.edu adresinden alınmıştır.

Atlas, R.M.,1994. Microorganisms In Our World. University of Luisville, Luisville Kentucky. Ayaz, M. ve Demirkuş, N. (2017). Sanal ve nesnel teknolojik öğretim araçlarını kullanarak fen bilimleri ders materyali geliştirmesine yönelik örnek çalışmalar. YYÜ Ĕ̈itim Fakültesi Dergisi, 14(1), 1257-1376.doi:http://dx.doi.org/10.23891/efdyyu.2017.48

Bakırcı, H. (2010). Üniversiteler düzeyinde fen bilgisi öğretmen adaylarının branşlara (fizik, kimya ve biyoloji) karşı tutumlarının incelenmesi. Yüzüncü Yıl Üniversitesi Fen Bilimleri Enstitüsü Dergisi, 15(1), 75-81.

Bozcuk, S., (1995).Genel Botanik. Hatipoğlu Yayınevi, Ankara.

Börü, S., Öztürk, E. ve Cavak, Ş. (2002). Lise 1 Biyoloji. MEB. Devlet Kitapları, Milli Eğitim Basımevi. İstanbul.170-172.

Campbell, N.A. (1999). Biolgy. World Student Series, Addison-Wesley.574-576.

Claude, A.V. (1979). Biology, Çevirenler: Şişli ve Arkadaşları Milli Eğitim Basımevi.

Cihangir, Ö. (2009). Biyoloji ile ilgili önemli kavramlara ilişkin ders video materyali geliştirme. Yüksek lisans tezi, Yüzüncü Y1l Üniversitesi, Fen Bilimleri, Enstitüsü Van. http://www.biyolojiegitim.yyu.edu.tr/kf/oz/oz.html adresinden alınmıştır. 
Demirkuş, N.( 2009a). Fen teknoloji ve toplum ders notu.5 Mart 2019 tarihinde http://www.biyolojiegitim.yyu.edu.tr/ders/ftt.htmadresinden alınmıştır.

Demirkuş, N.( 2009b). Öğretim teknolojisi ve materyal geliştirmeders notu.5 Mart 2019 tarihinde http://www.biyolojiegitim.yyu.edu.tr/ders/otm.htm adresinden alınmıştır.

Demirkuş, N.( 2009c). Özel öğretim yöntemleri l ders notu. 5 Mart 2019 tarihinde http://www.biyolojiegitim.yyu.edu.tr/ders/oo1.htmadresinden alınmıştır.

Demirkuş, N.( 2009d). Biyolojide önemli kavramlar ders notu. 5 Mart 2019 tarihinde http://www.biyolojiegitim.yyu.edu.tr/ders/kav.htmadresinden alınmıştır.

Demirkuş, N.(1999). Fen bilgisi öğretim yöntemleri ve uygulamalarının verimli hale getirilmesi, D.E.ய̈. Buca Eğitim Fakültesi Dergisi, Özel Sayı, 11 (1999) 414425.

Demirkuş, N. ve Gülen, S.(2017), Popüler fizik kavramları içeren görsel ders materyali geliştirme çalışması. Yüzüncü Yıl Üniversitesi Eğitim Fakültesi Dergisi, 14(1), 320-338. http://dx.doi.org/10.23891/efdyyu.2017.12

Demirkuş, N., Acar, E.ve Gülen, S. (2018), Popüler teknoloji kavramlarının eğitiminde görsel materyal geliştirme çalışması. YYÜ Eğitim Fakültesi Dergisi, 15(1), 723-748. http://dx.doi.org/10.23891/efdyyu.2018.85

Demirkuş, N., Bozkurt, T., ve Gülen, S. (2017), Popüler çevre kavramlarının eğitiminde görsel materyal geliştirme çalışması. Ahi Evran Üniversitesi Kırşehir Eğitim Fakültesi Dergisi (KEFAD), 18(Özel Say1), 145-157.

Demirkuş, N., Ertaş, A., ve Gülen, S. (2018), Mikrobiyolojik kavramların öğretilmesine ilişkin ders materyali geliştirme çalışması, Kırşehir Eğitim Fakültesi Dergisi, 19(3), 25612572. DOI:10.29299/kefad.2018.19.03.021

Demirkuş, N., İlçin, M. (2016). Yabancı-Yeni Biyolojik Kavramların Türkçeleştirilmesi ve Sanal Ders Materyalinin Hazırlanması, YYÜ Eğitim Fakültesi Dergisi, Cilt: XIII, Sayı: I,383-410.

Gen Bilim, (2011). Gen Bilim Sitesi Arşiv Tarama, 5 Eylül 2019. http://archive.fo/www.genbilim.com adresinden alınmıştır.

Gülen, S. (2016a). Tool of association concept; volume of concept. Participatory Educational Research, Special Issue 2016-II, 45-50. http://dx.doi.org/10.17275/per.16.spi.2.5

Gülen, S. (2016b). Fen-teknoloji-mühendislik ve matematik disiplinlerine dayalı argümantasyon destekli fen öğrenme yaklaşımının öğrencilerin öğrenme ürünlerine etkisi. Doktora Tezi, Ondokuz Mayıs Üniversitesi Eğitim Bilimleri Enstitüsü, Samsun. 
Gülen, S. (Kasım, 2015). Tool of associationconcept; volume of concept. II. International Dynamic, Explorativeand Active Learning (IDEAL) Conference, Amasya.

Gülen, S.(2018).Using volume of concept in the class environment. Journal of Technology and Science Education, 8(4), 205-213. https://doi.org/10.3926/jotse.362

Gülen, S. ve Demirkuş, N. (2014a). Görsel materyalin öğrenci başarısına etkisi. Saarbrücken: Türkiye Âlim Kitapları.

Gülen, S.ve Demirkuş, N. (2018). Sanal ders materyali tasarımı üzerine bir çalışma. 1th International Turkish-Russian World Academic Researches Congress, 14-16 Aralık, Ankara, Turkey.

Gülen, S.ve Demirkuş, N., (2014). Güneş sistemi ve ötesi: uzay bilmecesi” ünitesinde, görsel materyalin öğrenci başarısına etkisi. Yüzüncü Yıl Üniversitesi Eğitim Fakültesi Dergisi, 11(1), 1-19.

Gürlek, M.( 2019). Ortaöğretim biyoloji (botanik) öğretiminde anlam çözümleme tabloları, kavram ağları ve kavram haritalarının uygulanması, Uluslararası Bilim ve Eğitim kongresi (UBEK-ICSE), S. 627-638. 21-24 Mart, Afyonkarahisar

Hacettepe Üniversitesi, (2011). Hacettepe üniversitesi biyoloji topluluğu, 5 Mart

tarihinde www.bioclub.hacettepe.edu.tradresinden alınmıştır.

İstanbul Teknik Üniversitesi (2011).İstanbul teknik üniversitesi moleküler biyoloji ve genetiği, 5 Mart 2019 tarihinde www.bio.itu.edu.tr adresinden alınmıştır.

Kiziroğlu, İ., 1988. Günümüzde biyoloji dersi ve amaçlart. Hacettepe Üniversitesi Eğitim Fakültesi Dergisi, (3): 243-250.

Korkmaz, S., Bulut, Ö., Sağdıç, D. (1998). Lise 3 biyoloji. MEB. Devlet Kitapları, Milli Eğitim Basımevi. İ́stanbul.194-197.

MEB Komisyon(2011).12. Sinıf biyoloji ders kitabı, MEB. Devlet Kitapları, Milli Eğitim Basımevi, 264, İstanbul.

Mission, R. (2011). The fish out of time, 5 Mart 2019 tarihinde www.dinofish.com adresinden alınmıştır.

Öztürk, M., Akdeniz, A.R. ve Bakırcı, H. (2017). Bilgisayar destekli öğretim uygulamalarının ortaokul öğrencilerinin bilimsel düşünme becerilerine etkisi. YYÜ Eğitim Fakültesi Dergisi, 14(1), 611-639. http://dx.doi.org/10.23891/efdyyu.2017.24

Seçmen, Ö. ve ark. (1995).Tohumlu Bitkiler sistematiği. Ege Üniversitesi, Fen Fakültesi, Kitaplar Serisi No:116, İzmir. 333-359. 
Sucu, A., Bayar, S. ve Küpeli, M. (2001). Lise 2 Biyoloji. MEB. Devlet Kitapları, Mili Eğitim Basımevi. İstanbul.165-169.

Taş, E., Gülen, S. Öner, Z., ve Özyürek, C. (2015).The effects of classic and web-designed conceptual change texts on the subject of water chemistry.International Electronic Journal of ElementaryEducation, 7(2), 263-280.

Tootlille, E.(1983). The Penguin Dictionary of Botany, Penguin Books.

Van Yüzüncü Yıl Üniversitesi, (2019). Eğitim fakültesi biyoloji eğitimi anabilim dalı web sayfası http://biyolojiegitim.yyu.edu.tr/makale.html, http://nadidem.net/makale.html, erişim Tarihi 5 Mart 2019.

\section{Summary}

Problem Statement:It is important that foreign concepts related to biology are translated into Turkish. Different definitions and different illustrations of concepts are often not provided. The visuals expressing the definitions of the concept in the most accurate way are not presented on the internet and in the virtual environment. In addition, in the biology textbooks of the educational system in practice and in virtual environment; it seems that biological concepts are not given sufficient merit and privilege.

Purpose of the Study:In this study, it is aimed to translate the foreign concepts related to biology into Turkish, to give different definitions if any and to present them on the internet with pictures that express the definitions in the most accurate way. This study sets an example for the similarity in other fields. However, we believe that this kind of studies will reduce the misconception..

\section{Material and Methods:}

1340 images of 120 glass praparats in the Material Development and Preparation Room of the Department of Biology Education, Faculty of Education, Van Yüzüncü Y1l University were utilized. Various media sources have been used. Google search engine; The definitions of "biological concepts", "misconception" and "biology concepts" were searched according to screening rules.Images and descriptions of many concepts have been downloaded from the internet with the Google search engine.

Articles from the previous issues of TUBITAK Science and Technology Journal, which contain concepts related to biology, were utilized on the internet (Van Yüzüncü Y1l University, 2019). The definitions of various biology dictionaries have been utilized from these articles. In 
addition, photographs taken by the thesis supervisor about biology and information in the lecture notes were used.

In particular, Turkish Language Institution Dictionary, Redhouse Dictionary and Babylon Dictionaries were used to find the correct, logical, easy-to-use Turkish equivalent of the concepts. Nearly 15000 images and virtual student homework collections were used in the Biology Department Materials Development and Preparation Room. In total, 5000 images belonging to 800 concepts were selected in the study. Some of these images were taken from journals scanned by us. Some of them are images taken with microscope and camera and transferred to digital media.

All images are retouched with the Adobe Photoshop CS virtual graphics tool. Some have been resized and the original ones have names written on them.

All images in gif format have been converted to jpeg format and made ready for web.

Adobe Dreamweaver web editor and Adobe Fireworks programs using the concept definitions and pictures are matched, prepared for the Internet.

At this stage, approximately 40 virtual dictionaries were used.

The internet and intranet links of the concepts made available to the Internet are also pasted into the FlipAlbum 6.0 Suite virtual book and its CD is prepared. With the virtual book CD, it is possible to dynamically access both the links on the internet and the links within the virtual book on a computer connected to the internet.

\section{Findings and Discussion:}

In the research, for the correct perception and learning of the concepts related to biology; In addition to the properties of the selected material, different concepts may be shown or defined on the same material, and more than one material may be needed to explain the same concept.

During these studies, no comprehensive clear suggestions and studies were found to eliminate or solve the negative situations caused by incorrect and incomplete concept learning (misconceptions) or teaching related to biological concepts on print media and internet. Existing ones are also very inadequate.

It is important that this study sets an example for similar studies in other disciplines. Mentally more satisfying, open to discussion, visual, audible, defined (short film); the conceptdefinition relationship model was later presented by the same authors. (Demirkuş ve Gülen, 2017).

It was also determined that some concepts may have multiple definitions or multi- 
faceted meanings. For example: Some concepts may have different definitions in biology, chemistry or even sub-branches of biology. It was also determined that the same concept may have different meanings. It has been found that the opposite is also possible. Definitions of different concepts may overlap. For this purpose, while writing biology textbooks, it has been revealed that it should be written with a special model and method in terms of the concepts they contain.

\section{Conclusion and Recommendations:}

With this thesis; In order to learn more accurately the basic macroscopic concepts related to biology courses in primary, secondary and higher education and to complete the deficiencies, an internet web page and a virtual book CD were prepared.

In this respect, the information in the literature is insufficient and scattered. With this study, this information has been made more understandable. This is a preliminary study based on the links between image links and concepts at international level. The main purpose is to set an example for similar studies in other fields (Ayaz ve Demirkuş, 2017).

With this master's thesis work, the student has learned to use some graphic programs, web editor programs, real and virtual tools to prepare materials for digital media effectively and developed their skills.

Based on the data obtained from student assignments, applications and laboratory studies, a "Virtual Data Processing Method has been developed for virtual data collection, evaluation and processing in order to understand, learn, apply and use the concepts correctly in teaching.

The materials collected and prepared as a result of the activity and application in the Biology and Science Laboratories were transferred to the virtual environment. High quality and low cost virtual course material has been prepared. For this purpose; A visual repository of 5000 images was created, which included about 800 definitions of biology-related and important (most used in teaching) concepts.

http://biyolojiegitim.yyu.edu.tr/kav/indexa.htm, http://nadidem.net/kav/indexa.htm http://biyolojiegitim.yyu.edu.tr/la/index.htm, http://nadidem.net/la/index.htm http://biyolojiegitim.yyu.edu.tr/fbl/index.htm , http://nadidem.net/fbl/index.htm http://biyolojiegitim.yyu.edu.tr/lab/index.htm , http://nadidem.net/lab/index.htm Teaching the concepts is also recommended to pay attention to the following issues. 
-While preparing the course books, all the concepts they contain should be supported with visual, internet and virtual books with internal links.

-Concepts should be taught with visual, short film and animated CDs if possible.

-The concepts should be taught by discussion, question-answer, practice and similar methods.

-Concept courses should be placed at appropriate levels of education.

-The most understandable, easy-associative and logical equivalents of the concepts should be given.

-Annual reports of new (foreign) concepts should be prepared. These reports and recommendations should be discussed online.

-Concept teaching; the studies on updating and placing concepts in the mind should be intensified.

-The concepts should be graded according to their priority (as concepts in 1st, 2nd and 3rd degree) and they should be taught and updated. 